\section{Across the boundaries}

\author{
Interfaces and Free Boundaries: \\ Modeling, Analysis and \\ Computation \\ editor Mario Primicerio \\ Oxford University Press. 4/yr. £195, \$335 \\ (institutional), $£ 176, \$ 302$ (institutional, \\ online only), $£ 50, \$ 80$ (individual)

\section{Albert-László Barabás}

The alarming loss of biodiversity is accompanied by an increasing diversity of scholarly thought, as demonstrated by the rate at which specialized journals emerge. The survival of free thinking is guaranteed by safe havens for those sharing the same interests, tools or ideas, but they are scattered across disciplines.

Interfaces and Free Boundaries is one such safe haven, offering a fertile soil for applied and pure mathematicians trying to reach a common language in this rather fragmented and interdisciplinary field. The apparently eclectic selections of contributions, ranging from superconductivity to dendritic growth, offers a culture shock at first. However, the source of this diversity is hidden in the subtitle: Modeling, Analysis and Computation. And indeed, the journal does offer common ground for those interested in the computational and mathematical tools for dealing with interfaces and free boundaries, irrespective of discipline. As a result, experimentalists should beware: the papers clearly favour rigorous mathematics above phenomenology - probably in line with the intent of the editorial board, the great majority of whom come from applied maths departments.

But should you be an experimentalist or theorist faced with a free-boundary problem, this is the place to look for expertise, papers and ideas - the four issues published so far offer a wide spectrum of articles that touch on most of the techniques needed to master this field. And all this in a single journal, doing away with the need for often fruitless database searches or trips to various libraries across the campus. The best way to get the flavour of the journal is to visit its online edition, which displays the table of contents of the issues published so far. In this respect, Oxford University Press has done an excellent job, giving the journal all the perks it needs for survival, including an online edition, electronic submissions and a pleasing appearance, with the possibility of colour pictures.

Should you run to your librarian for a subscription? Look at the online version before you drop any other journal from the shelf. But if your budget can be stretched to include it, it will be an unselfish decision for any department, since people from other departments might wish to peek too. http://www3.oup.co.uk/infree/?LO Albert-László Barabási is in the Department of Physics, University of Notre Dame, Notre Dame, Indiana 46556, USA.

\section{Europe's hard forum for soft matter}

\section{The European Physical Journal E} - Soft Matter

editors-in-chief A. M. Donald, J.-F. Joanny, M. Möller \& G. Reiter

Springer. 12/yr. \$1,181 (US), DM1,872 plus carriage charges (Germany DM37.20;

elsewhere DM52.80)

\section{Steve Granick and Sung Chul Bae}

The study of 'soft matter' has burgeoned as an academic discipline during the past generation. Its prominence has matched the study of 'hard matter' - traditional condensedmatter physics. The scope of 'soft matter' is larger than physics, however. The preoccupation is with systems (polymers, biopolymers, membranes, self-assembled nanostructures) where the energetic interactions are commonly so 'soft' that complexity, disorder and the capacity to manipulate and tune structure and dynamics emerge in fundamentally new ways. The worldwide community is struggling to deal with the fact that these systems straddle so large a spectrum of traditional disciplines: not just physics, but also chemistry, biophysics and some mechanics.

Seven years ago these considerations led the American Physical Society to launch a new journal, Physical Review E, which immediately established itself as a premier archival journal in terms of quality and prestige. It is altogether fitting that the European Physical Society should do the same.
Here three distinguished European journals - Il Nuovo Cimento D, Journal de Physique and Zeitschrift für Physik B - seek rebirth in the launch of a blue-ribbon European journal devoted to this new discipline.

The journal's ambitious goal is to develop a wider readership and more eclectic submissions than would be expected of a physics journal. Among the articles published during the initial six months the quality is high, but the flavour is not yet really different from that of Physical Review E. Representation from other subfields of soft matter will probably grow. Every scientific research library will want to hold this blue-ribbon archival journal.

\section{http://www.link.springer.de/journals/epje}

Steve Granick is in the Departments of Materials

Science and Engineering, Physics, Chemistry and Chemical Engineering, University of Illinois. Sung Chul Bae is in the Department of Materials Science and Engineering, University of Illinois, Urbana, Illinois 61801, USA.

\section{Making way for complex issues}

\section{Nonlinear Phenomena in}

\section{Complex Systems}

editors-in-chief V. A. Gaisyonok \&

F. I. Kuvshinov

Education \& Upbringing, Belarus. 3/4/yr.

\$158 (institutional), \$98 (individual \& institutions from developing countries)

\section{William Ditto}

Small changes can often have fundamental effects on the behaviour of complex systems. This is self-evident in the proliferation of interdisciplinary journals devoted to nonlinear dynamics and complex systems. Amid this creative renaissance (or journalistic excess, depending on your viewpoint), new journals

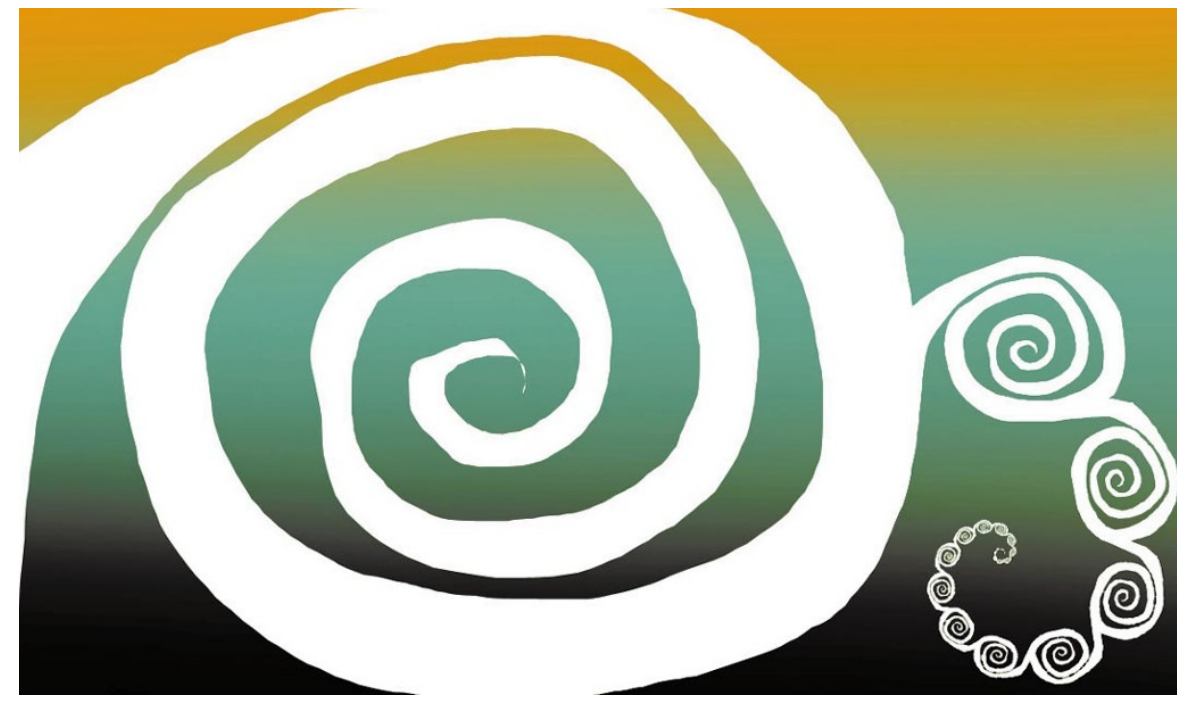


must provide a service to the scientific communities rather than just add to the overall explosive numbers of scientific papers.

Nonlinear Phenomena in Complex Systems delivers to the community in a couple of ways. First, it provides a mostly regional forum (primarily Central and Eastern European) for both experimental and theoretical research in interdisciplinary complex systems. Thus it gives both an editorial and a scientific voice to the many creative individuals who were previously relegated to the cloistered world of Soviet science journals. Lest those of us in the United States get too uppity, we should remember that it was only a few decades ago that Physical Review was considered a regional or 'colonial' journal.

But the journal must ultimately stand on quality alone, and the quality and content of the papers in Nonlinear Phenomena are rather uneven. One problem lies in the presentation of technical data. Topics covered range from esoteric mathematical proofs and formalisms to practical experimental research. Unfortunately, there seems to have been little editorial attempt to persuade the authors to make their papers more accessible to an interdisciplinary audience. This is an extremely important aspect and very hard to pull off.

Apart from issues of content, there are also problems with the quality of presentation. Specifically, the figures range in quality from adequate to unreadable. This at least must be addressed for the journal to survive.

On the positive side, there are articles from regional conferences that are quite stimulating. Clearly, a reader interested in the latest in interdisciplinary complex systems research would do better initially to peruse this journal's competitors, for example Chaos and the International Journal of Bifurcations and Chaos. But Nonlinear Phenomena is an improving publication that serves a regional audience with papers that range from the banal to the fascinating.

\section{http://ccisc.bas-net.by/npcs}

William Ditto is in the Georgia Tech/Emory Department of Biomedical Engineering, 315 Ferst Drive, Atlanta, Georgia 30332-0535, USA.

\section{Backing the n-word}

Journal of Nanoparticle Research editor-in-chief Mihail C. Roco

Kluwer. 4/yr. \$278 (institutional) $\$ 88$ (individual)

\section{Saul Tendler}

When Shakespeare penned the line "I do not like her name", he could have been thinking about nanotechnology. Derived from the Greek nanos for dwarf, it may revolutionize our lives through the creation of nanometrescale sensors, devices and machines. How- ever, early claims about the potential of the subject leave many people cautious about using the n-word.

The Journal of Nanoparticle Research seeks to embrace all things nanotechnology while avoiding its name. With a hard focus on nanoparticles, the scope of the journal includes fundamental science, chemical synthesis, modelling, simulations, instrument development and molecular/particulate self-assembly into higher-order architectures. This broad remit extends from the biological and chemical to the physical sciences. The first volume of the journal has attracted an impressive number of full papers, many from leading groups with international reputations. Perhaps unsurprisingly, the majority of the papers cover the production and properties of inorganic nanoparticulate systems.

The journal carries both long and short papers, reviews, technology notes and meeting reports. There are also policy papers on funding initiatives. Intriguingly, the journal allows papers directed towards education: the first edition has a splendid paper on making the nanoworld comprehensible for schools and beyond. Given the publication's specialist nature, though, it may be that some of this outreach activity will fall away over time.

There are many top-quality physicochemical journals that would publish much of the work found in the first volume. But such publications do not attract a sufficient critical mass of papers in this area to create a comprehensive view. With quality basic science, and applications assured in areas as diverse as catalysis and drug delivery, Journal of Nanoparticle Research provides a cross-disciplinary focal point for the subject. Success is assured if it can maintain this focus.

\section{http://www.wkap.n1/journalhome.htm/1388-0764}

Saul Tendler is at the School of Pharmaceutical Sciences, University of Nottingham, Nottingham NG7 2RD, UK.

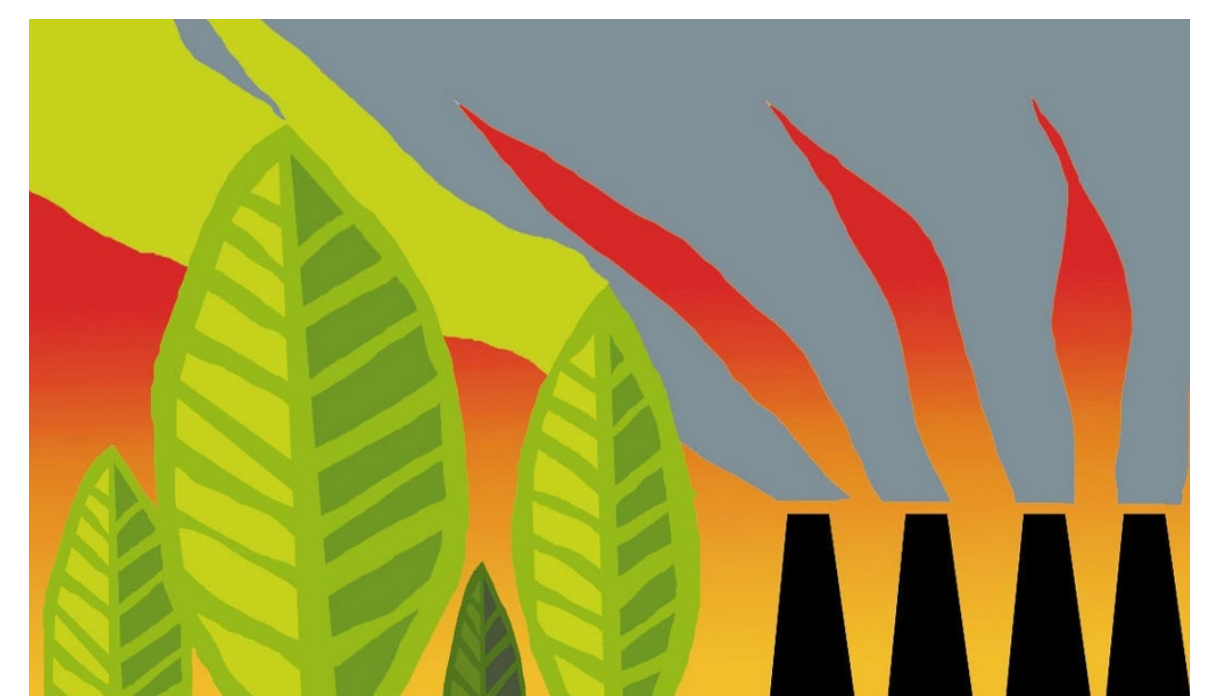

Plant power against pollution

\section{International Journal of \\ Phytoremediation}

editor-in-chief Guy R. Lanza

CRC Press. 4/yr. \$385 (institutional, print

plus online), $\$ 295$ (institutional, print or

online), \$125 (to members of the Association for the Environmental Health of Soils)

\section{William Purvis}

Phytoremediation relies on the natural properties of plants to help clean up hazardous metal and organic wastes. Bioremediation with microorganisms was used in the Exxon Valdez oil spill in Alaska and also after the Chernobyl nuclear power plant accident. The idea of using plants to extract, inactivate, transform or degrade contaminants is appealing - they bring 400 million years of evolutionary processes across hugely diverse groups. Moreover, increased environmental awareness and the need for sustainable development have sparked intense activity in this area across the world, particularly in the United States.

Appropriately, the first issue of International Journal of Phytoremediation features an invited and readable review article by renowned ecotoxicologist André Sobolewski, who discusses the biological and nonbiological processes responsible for removing metal from mine drainage by wetlands. This is the classic application, and uptake by plants is only part of the story. Bacteria may accumulate and transform metals which may also be sorbed to organic matter and inorganic materials.

Phytoremediation is an interdisciplinary subject, its success depending on diverse areas of science that include genetics, physiology, biochemistry, microbiology, soil science, geochemistry and engineering. This journal necessarily takes a broad view 